Reprod. Nutr. Dévelop., 1985, 25 (1 B), 331-332.

\title{
Development and regulation of ketogenesis in isolated hepatocytes from newborn rabbits
}

\author{
P. H. DUÉE，J. P. PÉGORIER, C. KOHL, J. GIRARD
}

Centre de Recherches sur la Nutrition, C.N.R.S.,

9, rue Jules-Hetzel, 92190 Meudon-Bellevue, France.

Physiological hyperketonemia develops after birth in most mammals (Girard and Ferré, 1982). Since the body lipid stores in newborns are usually low, ketone body precursors are supplied by milk which is a high-fat diet. However, in a few species like rabbits, the fetus is endowed with large hepatic lipid stores and starved newborns show an increase in blood ketone body concentrations 6 to $12 \mathrm{~h}$ after birth (Callikan et al., 1979). The aim of the present study was to determine the importance of endogenous hepatic triglyceride stores in the development of ketogenesis.

Rabbits of the New Zealand White strain were delivered by caesarean section after neck dislocation of the mother, either at term (32 days postcoitum) or prematurely ( 29 days postcoitum). They were immediately placed in an incubator at $36{ }^{\circ} \mathrm{C}$ (thermal neutrality) and $70 \%$ relative humidity and were fasted for 0,6 , 12,24 or $48 \mathrm{~h}$ after birth. Hepatocytes, prepared by the method described by Berry and Friend (1969) with some modifications as described by El Manoubi et al. (1983), were incubated at $37^{\circ} \mathrm{C}$ for either 60 or $90 \mathrm{~min}$ in a final volume of $4 \mathrm{ml}$ of Krebs-Henseleit medium.

As reported previously (El Manoubi, Ferré and Girard, 1981), the rates of ketone body production from both endogenous precursors and exogenous fatty acids (oleate $1 \mathrm{mM}$ or octanoate $2 \mathrm{mM}$ bound to $3 \%$ fat-free albumin) were very low at birth and increased slightly during the first 6 neonatal hours. These ketogenic rates increased five to six times between 6 and $12 \mathrm{~h}$ and then remained high until $48 \mathrm{~h}$ after birth. The hydrolysis of hepatic triglyceride stores was sufficient to support the ketogenic capacity of the hepatic cells at $24 \mathrm{~h}$; between 24 and $48 \mathrm{~h}$ after birth, liver triacylglycerol content dropped and the rate of ketogenesis from endogenous precursors decreased by $30 \%$. Nevertheless, the maximal rate of ketogenesis could be restored by the addition of oleate or octanoate.

To determine whether the increase in hepatocyte ketogenic capacity in newborn rabbits was triggered by birth itself or by chronological factors, we studied the rate of ketogenesis from endogenous fatty acids and from oleate or octanoate in hepatocytes isolated from premature newborns fasted for $24 \mathrm{~h}$ at $36^{\circ} \mathrm{C}$. The rates of ketogenesis from endogenous or exogenous precursors were 
very low in hepatocytes isolated from 29-day old fetal rabbits and were in the same range as in fetal rabbits at term. Twenty-four hours after delivery, the rates of ketone body production from endogenous or exogenous precursors increased by 20 -fold.

These data suggest that in vitro liver triglyceride breakdown was very high, revealing the ketogenic capacity of the liver. To obtain information concerning the contribution of the lysosomal pathway in hepatic triglyceride degradation, hepatocytes of 24-hour old fasted newborns were preincubated for $30 \mathrm{~min}$ in the absence or presence of lysosomotropic agents (chloroquine : $0.3 \mathrm{mM} ; \mathrm{NH}_{4} \mathrm{Cl}$ : $10 \mathrm{mM}$ ) or of specific inhibitors of lysosomal triglyceride lipase (glycodiazine : $10 \mathrm{mM}$; esterastin : $20 \mu \mathrm{M})$. These hepatocytes were further incubated for $60 \mathrm{~min}$ with or without oleate. The addition of lysosomotropic agents or of lysosomal lipase inhibitors decreased the rates of ketogenesis from the endogenous precursors by 60 to $70 \%$. Furthermore, the addition of exogenous oleate restored a normal rate of ketone body production, indicating that fatty acid oxidation was not impaired by the lysosomotropic agents or lipase inhibitors.

In conclusion, the ketogenic capacity of hepatocytes from starved newborn rabbits increased a few hours after birth to reach a maximal value at $12 \mathrm{~h}$ of age. Ketone bodies were formed from fatty acids produced by the lysosomal degradation of hepatic triglyceride stores via the activation of an acid triglyceride lipase.

10 Réunion du groupe Développement I.N.R.A., Rennes, 9-10 mai 1984.

\section{References}

BERRY M. N., FRIEND D. S., 1969. High-yield preparation of isolated rat liver parenchymal cells. J. Cell Biol., 43, 506-520.

CALLIKAN S., FERRÉ P., PÉGORIER J. P., GIRARD J. R., MARLISS E. B., ASSAN R., 1979. Fuel metabolism in fasted newborn rabbits. J. Develop. Physiol., 1, 267-281.

EL MANOUBI L., FERRE P., GIRARD J., 1981. Development of ketogenesis in the newborn rabbit : temporal studies in isolated hepatocytes. Biochem. Soc. Transac., 9, 53-54.

EL MANOUBI L., CALLIKAN S., DUÉE P. H., FERRÉ P., GIRARD J., 1983. Development of gluconeogenesis in isolated hepatocytes from the rabbit. Am. J. Physiol., 244, E24-E30.

GIRARD J., FERRE P., 1982. Metabolic and hormonal changes around birth, 517-551. In JONES C. T., Biochemical development of the fetus and neonate. Elsevier biomed. Press, Amsterdam. 